\title{
Drought Tolerance Associated with Proline and Hormone Metabolism in Two Tall Fescue Cultivars
}

\author{
Da Man, Yong-Xia Bao, and Lie-Bao Han ${ }^{1,2}$ \\ Turfgrass Research Institute, Beijing Forestry University, Beijing, China \\ 100083
}

\author{
Xunzhong Zhang ${ }^{1,2}$ \\ Department of Crop and Soil Environmental Sciences, Virginia Polytechnic \\ Institute and State University, Blacksburg, VA 24041
}

Additional index words. drought tolerance, hormone, physiology, proline, tall fescue

\begin{abstract}
Drought stress is a major factor in turfgrass management; however, the underlying mechanisms of turfgrass drought tolerance are not well understood. This greenhouse study was designed to investigate proline and hormone responses to drought stress in two tall fescue [Festuca arundinacea (Schreb.)] cultivars differing in drought tolerance. The two cultivars, Van Gogh (relatively drought-tolerant) and AST7002 (relatively drought-sensitive), were established and grown under either well-watered (maintaining $90 \%$ container capacity) or drought stress $(\approx 26 \%$ container capacity) and then re-watered. Drought stress reduced turfgrass quality, relative leaf water content (LWC), leaf indole-3-acetic acid (IAA) and cytokinin zeatin riboside (ZR) content, and increased proline and abscisic acid (ABA) content. 'Van Gogh' had greater turfgrass quality rating, $\mathrm{LWC}$, proline, $\mathrm{ABA}$, and ZR content relative to 'AST7002' under drought stress conditions. At the end of drought stress, leaf proline, $\mathrm{ZR}$, and ABA content were $32 \%, 43 \%$, and $50 \%$ higher in 'Van Gogh' relative to 'AST7002', respectively. No cultivar difference was observed under well-watered conditions. The results of this study suggest that the proline, $A B A$, and $Z R$ content are associated with drought tolerance. Selection and use of the cultivars with higher proline, ABA, and ZR content under drought stress may be a practical approach to improve tall fescue drought tolerance.
\end{abstract}

Drought is a major limiting factor of turfgrass culture in many parts of the world. Drought stress suppresses growth and causes a loss of turf quality (Carrow and Duncan, 2003; Zhang et al., 2009). Plants exhibit various physiological and biochemical responses to drought stress. Accumulation of osmotic compounds such as proline and changes in phytohormones are some of the most common responses of plants to drought stress (Hare et al., 1997).

Proline, an amino acid, is a compatible solute involved in cell osmotic adjustment (OA) and protection of cell components during dehydration (Zhang et al., 2009). Osmotic adjustment helps to maintain cell turgor, which can allow cell enlargement and plant growth during water stress; and it can allow stomata to remain at least partially open and $\mathrm{CO}_{2}$ assimilation to continue at water potentials that would be otherwise inhibitory (Alves and Setter, 2004). Proline

Received for publication 25 Feb. 2011. Accepted for publication 29 Apr. 2011.

This research was supported by the Specific Programs in Graduate Science and Technology Innovation of Beijing Forestry University (NO.BLYJ201101), Beijing, China.

${ }^{1}$ Da Man and Yong-Xia Bao contributed equally to this work.

${ }^{2}$ To whom reprint requests should be addressed; e-mail hanliebao@163.com; xuzhang@vt.edu. also functions as a free radical scavenger and suppresses free radical-mediated damage during drought stress. Several studies have indicated that proline content increases during drought stress, and proline accumulation is associated with improvement in drought tolerance in tall fescue and other plants (Seki et al., 2007; Zhang et al., 2009).

There is increasing evidence showing that plant physiological fitness is largely governed by hormonal balance (Itai, 1999; Zhang et al., 2009). Abscisic acid plays an important role in stress signal network and it is postulated to mediate stress-induced stomatal closure (Xiong et al., 2002; Zhu, 2002). It has been reported that ABA increased in response to drought stress in tall fescue (Zhang et al., 2009) and other crop plants (Domash et al., 2006; Lopez-Garbonell et al., 1994; Pustovoitova et al., 2004; Yang et al., 2001). Desikan et al. (2004) pointed out that drought stress increases ABA synthesis and redistribution. The change in ABA initiates an intricate network of signaling pathways in guard cells leading to stomatal closure and conservation of water.

Cytokinins exhibit antisenescence properties (Musgrave, 1994). Cytokinins delay the senescence process probably by maintaining the integrity of the tonoplast membrane (Thimann, 1987). Zeatin and its sugar derivatives (zeatin riboside and zeatin ribotidedihydrozeatin and isopentenyl adenine) are the most common naturally occurring cytokinins (Strivastava, 2002). Bano et al. (1993) noted that cytokinin concentration in xylem sap declined after water deprivation and increased again after re-watering. It has been documented that the plants with higher cytokinins exhibited greater drought tolerance and exogenous cytokinins (such as zeatin riboside) can improve turfgrass tolerance to drought stress (Zhang and Ervin, 2004; Zhang and Schmidt, 1999, 2000). IAA is associated with root initiation and growth (Nordstrom et al., 1991; O'Donnell, 1973) Recent study has shown that leaf tissue IAA content was positively correlated with drought tolerance and exogenous indole-3-butyric acid increased endogenous IAA and improved tall fescue drought tolerance (Zhang et al., 2005, 2009). It was also reported IAA content increased as plants adapted to drought stress (Pustovoitova et al., 2004; Sakurai et al., 1985).

Tall fescue [Festuca arundinacea (Schreb.)], a cool-season turfgrass, is widely used for home lawns, recreational surfaces, and roadsides in the temperate to semitropical regions and experiences frequent summer drought stress in many areas (Zhang et al., 2009). There are many different cultivars that vary widely in drought tolerance. 'Van Gogh' is a cultivar with excellent drought tolerance and 'AST 7002' is a cultivar with relatively poor drought tolerance (National Turfgrass Evaluation Program, 2008). Little study has been reported on mechanisms of drought tolerance-associated proline and hormone metabolism in different tall fescue cultivars. Understanding the physiological mechanism of turfgrass drought tolerance is important for breeder to develop drought-tolerant cultivars and turfgrass practitioners to improve turfgrass quality under drought stress. Our objectives were to investigate proline and hormone metabolism of the two tall fescue cultivars (Van Gogh and AST7002) contrasting in drought tolerance and to examine if variation between the cultivars differing in drought tolerance is associated with proline and hormone metabolism.

\section{Materials and Methods}

Tall fescue culture and drought stress treatment. This study was conducted at the Turfgrass Research Institute at Beijing Forestry University, Beijing, China, from May 2009 to Mar. 2010. Two tall fescue cultivars, Van Gogh (relatively drought-tolerant) and AST7002 (relatively drought-sensitive), were planted in pots $(15 \mathrm{~cm}$ diameter, $15 \mathrm{~cm}$ deep) filled with silt loam soil (fine-loamy, mixed mesic Typic Hapludult) mixed with a small amount of sand (4:1) at a seeding rate of $30 \mathrm{~g}$ pure live seeds $/ \mathrm{m}^{2}$. The grass was grown in a greenhouse with photosynthetically active radiation at $400 \mu \mathrm{mol} \cdot \mathrm{m}^{-2} \cdot \mathrm{s}^{-1}$ (at $1400 \mathrm{Hr}$ ) and $24 / 21^{\circ} \mathrm{C}$ (day/night) and watered by hand three times a week. After the grass was grown for 8 weeks, half of the pots were subjected to dry down and the remaining pots were irrigated to approximately 
maintain container capacity. Nitrogen $(20 \mathrm{~N}-$ $8.8 \mathrm{P}-16.6 \mathrm{~K}$ ) was applied at $5 \mathrm{~g} \cdot \mathrm{m}^{-2}$ before planting and every month thereafter. The grass was mowed weekly to $\approx 9 \mathrm{~cm}$ with scissors.

For drought stress treatment, the tall fescue was subjected to dry down by allowing soil moisture to drop gradually to $\approx 26 \%$ of container capacity ( $6 \%$ soil water content) and holding soil moisture in this range for $2 \mathrm{~d}$. Then, all drought treatment pots were rewatered to $90 \%$ container capacity $(25.8 \%$ soil water content) on Day 10 . It took $8 \mathrm{~d}$ for soil moisture to decrease to $\approx 26 \%$ container capacity in this study. Soil moisture content (top $5 \mathrm{~cm}$ deep soil) was determined using a ThetaProbe soil moisture sensor (Type ML1; Delta-T Devices Ltd., Cambridge, U.K.).

Measurements. Physiological parameters were determined during dry down and recovery periods. Samples of leaf tissues for biochemical constituents were taken from the top $1.5 \mathrm{~cm}$ of the canopy at $0,4,8,12,16$, and $20 \mathrm{~d}$ of treatment, placed in plastic sample bags, frozen with liquid nitrogen, and stored at $\approx 80{ }^{\circ} \mathrm{C}$ for analysis of proline, IAA, cytokinin, and ABA contents.

Turfgrass quality, relative leaf water content, leaf wilting, and root growth. Turfgrass quality was rated on a visual scale of 1 to 9 with 9 indicating the best quality (very dark green, dense, uniform, turgid shoots) and 1 indicating completely dead or brown shoots (Waddington et al., 1992). A rating of 6 represents minimum acceptability. Leaf wilting was rated based on a visual scale of $0 \%$ to $100 \%$ with $100 \%$ indicating complete, permanent wilting of the canopy.

Relative leaf water content was determined according to Gonzalez and GonzalezVilar (2001) with some modifications. Briefly, fresh leaf $(100 \mathrm{mg})$ was sampled and weighed (fresh weight), then placed in distilled water and shaken for $4 \mathrm{~h}$. The samples were weighed [total weight (TW)] and weighed [dry weight (DW)] again after the samples were dried at $65^{\circ} \mathrm{C}$ for $48 \mathrm{~h}$. The relative leaf water content is calculated based on the following formula:

$$
\mathrm{LWC}(\%)=(\mathrm{FW}-\mathrm{DW}) /(\mathrm{TW}-\mathrm{DW}) \times 100
$$

Root mass per pot was determined at the end of the experiment by removing whole plants from the pots and washing the media from the roots. The roots were dried at $65^{\circ} \mathrm{C}$ for $48 \mathrm{~h}$ and weighed.

Leaf proline content. Frozen leaf samples $(50 \mathrm{mg})$ were crushed with liquid nitrogen and extracted with a pestle in an ice-cold mortar with $4.5 \mathrm{~mL}$ of $3 \% 5$-sulfosalicylic acid. The homogenate was filtered with a filter paper (\#2) and the filtrate was used for the analysis. Proline content was determined spectrophotometrically at $520 \mathrm{~nm}$ (Bates, 1973).

Extraction, purification, and determination of plant hormones. The leaf IAA and ABA were extracted according to Edlund et al. (1995) and Zhang et al. (2009) with some modifications. Leaf tissue $(500 \mathrm{mg})$ was ground with a mortar and a pestle in liquid nitrogen and homogenized in $5 \mathrm{~mL}$ Na-phosphate buffer $(0.05 \mathrm{M}, \mathrm{pH} 7.0)$ containing $0.02 \%$ sodium diethyldithiocarbamate as an antioxidant and the hormones were extracted by continuous shaking for $2 \mathrm{~h}$ at $4{ }^{\circ} \mathrm{C}$. The samples were transferred into test tubes after extraction and $\mathrm{pH}$ was adjusted to $\approx 2.6$ with $1.0 \mathrm{M} \mathrm{HCl}$. The sample was slurried with Amberlite XAD-7 (Sigma, St. Louis, MO) for $30 \mathrm{~min}$. After removal of the buffer, the XAD7 was washed two times with $4 \mathrm{~mL}$ of $1 \%$ acetic acid before being slurried two times with $5 \mathrm{~mL}$ dichloromethane for $30 \mathrm{~min}$ (Edlund et al., 1995). The combined dichloro-

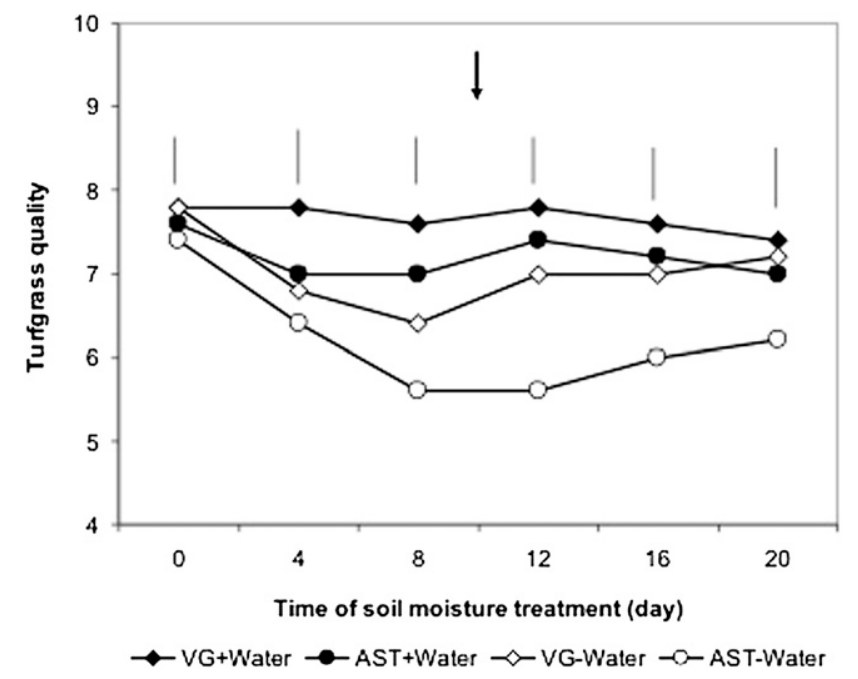

Fig. 1. Turfgrass quality ( 1 to 9 , with 9 indicating the best) in two tall fescue cultivars under well-watered ( $90 \%$ container capacity) and drought stress conditions (the soil moisture content reduced to $26 \%$ container capacity in $8 \mathrm{~d}$ and then re-watered at Day 10 and brought back to $90 \%$ container capacity for recovery). Vertical bars represent least significant difference (0.05) for treatment comparison at each sampling date. VG+ water and AST+ water indicate 'Van Gogh' and 'AST7002' under well-watered conditions; VG-water and AST-water indicate 'Van Gogh' and 'AST7002' under drought stress conditions. The arrow indicates the time of re-watering.

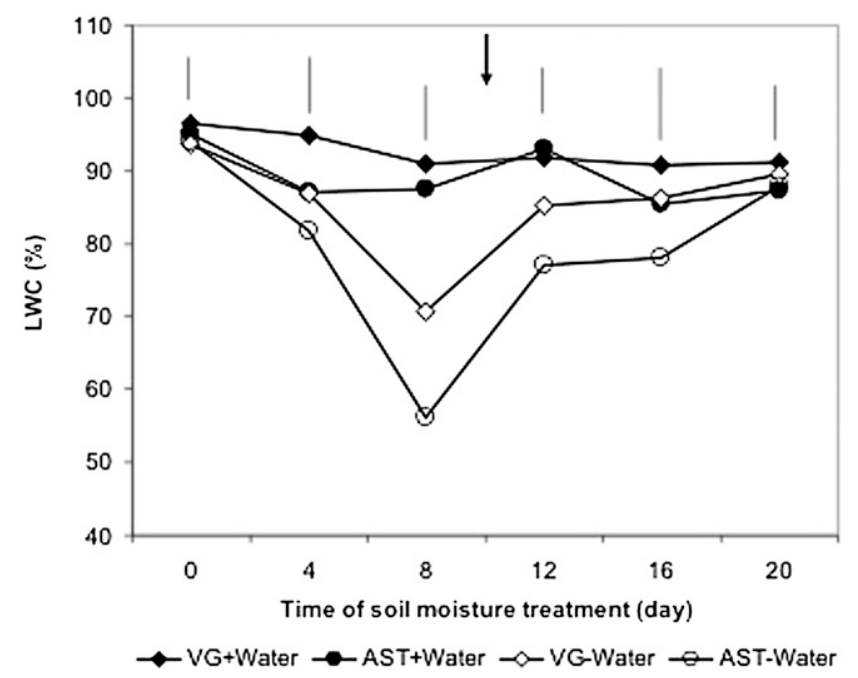

Fig. 2. Relative leaf water content (LWC; \%) in two tall fescue cultivars under well-watered $(90 \%$ container capacity) and drought stress conditions (the soil moisture content reduced to $26 \%$ container capacity in $8 \mathrm{~d}$ and then re-watered at Day 10 and brought back to $90 \%$ container capacity for recovery). Vertical bars represent least significant difference $(0.05)$ for treatment comparison at each sampling date. VG+ water and AST+ water indicate 'Van Gogh' and 'AST7002' under well-watered conditions; VG-water and AST-water indicate 'Van Gogh' and 'AST7002' under drought stress conditions. The arrow indicates the time of re-watering. 
saline ( $\mathrm{pH}$ 7.0) and filtered with an acrodisc $13-\mathrm{mm}$ syringe filter with $0.2-\mu \mathrm{m}$ nylon membrane before being analyzed.

The IAA, ABA, and t-ZR were analyzed using the SCL-10A VP HPLC system (Shimazu, Japan) according to the methods of Wang et al.(2008) with some modifications (Xiao et al., 2001; Yang et al., 2007). An aliquot $(10 \mu \mathrm{L})$ of the filtered samples was injected into a Shim-Park C18 VP-ODS chromatographic column $(150 \mathrm{~mm} \times 4.6 \mathrm{~mm}$, $5 \mu \mathrm{m})$ with isocratic elution at a flow rate of $0.7 \mathrm{~mL} \cdot \mathrm{min}^{-1}$ at $30{ }^{\circ} \mathrm{C}$ using methanol and $0.075 \%$ acetic acid as a mobile phase $(45: 55, \mathrm{v} / \mathrm{v})$. Detection of different hormones was carried out at $254 \mathrm{~nm}$ by a Shimazu SPD10A VP ultraviolet detector and cochromatography with authentic standards (Sigma). The retention times and the wavelength of characteristic absorbance of different hormones were determined with authentic standard compounds, respectively. Identification of the samples was carried out by comparison of retention times and characteristic absorbance of the eluting peaks with authentic standard compounds (Wang et al., 2008). All values were corrected against internal standards with known concentrations of different hormones.

Experimental design and statistical analysis. A split-plot design was used with soil moisture as the main plots and cultivar as the subplots. There were four replicates. The effects of cultivar, soil moisture, and their interactions were analyzed using an analysis of variance (SAS Institute Inc., 2004). To compare the effects of the four treatments (two cultivars, Van Gogh and AST7002, under well-watered and drought stress conditions), mean separations were performed using a Fisher's protected least significant difference at the $5 \%$ probability level (SAS Institute Inc., 2004).

\section{Results}

The interactions between the cultivar and the soil moisture treatment were not statistically significant for all parameters examined in this study. The four treatments were compared based on the data at each sampling date at the $5 \%$ probability level.

Turfgrass quality, leaf water content, leaf wilting, and root weight. Drought stress reduced turfgrass quality in both cultivars (Fig. 1). After re-watering, turfgrass quality recovered gradually to the acceptable level (rating 6 or greater). The turfgrass quality was higher in 'Van Gogh' relative to 'AST7002' as measured at Days 8, 12, 16, and 20 during drought stress and recovery periods (Fig. 1). At Day 8, the turfgrass quality was $14 \%$ greater in 'Van Gogh' relative to 'AST7002'. Two d after re-watering, the turfgrass quality in 'Van Gogh' increased by $9 \%$, but no change was observed in 'AST7002'. No difference in turfgrass quality was found between the two cultivars under well-watered conditions (Fig. 1).

Similar to turfgrass quality, LWC declined during drought stress and recovered after re-watering in both cultivars (Fig. 2). The LWC was reduced by $24 \%$ in 'Van Gogh' and $40 \%$ in 'AST7002' as measured at $\mathrm{d} 8$ under drought stress conditions. 'Van Gogh' had greater LWC than 'AST7002' as measured at Days 8, 12, and 16. No difference in LWC was observed between the two cultivars under well-watered conditions (Fig. 2).

Significant difference in leaf wilting was observed between the two cultivars (Fig. 3). Leaf wilt rating of 'AST7002' was $180 \%$ greater than 'Van Gogh' as measured at Day 4 and $76 \%$ at Day 8 , respectively. There was no difference between treatments in root weight (data were not shown).

Leaf proline content. Leaf proline content increased in response to drought stress (Fig. 4). Drought stress caused an increase in leaf proline content by 6.8 -fold in 'Van Gogh' and 6.6-fold in 'AST7002', respectively, when compared with the well-watered treatment as measured at Day 8. 'Van Gogh' had greater proline content than 'AST7002' as measured during drought stress and recovery periods. At Day 8 , the proline content in 'Van Gogh' was 32\% higher than that in 'AST7002'. Under well-watered conditions, leaf proline content was similar in the two cultivars (Fig. 4).

Leaf abscisic acid, indole-3-acetic acid, and zeatin riboside content. The leaf $\mathrm{ABA}$ content increased during drought stress and declined after re-watering (Fig. 5). Cultivar difference in $\mathrm{ABA}$ content was found during drought stress and recovery periods with the ABA content in 'Van Gogh' being higher than that in 'AST7002'. At d 8, the ABA

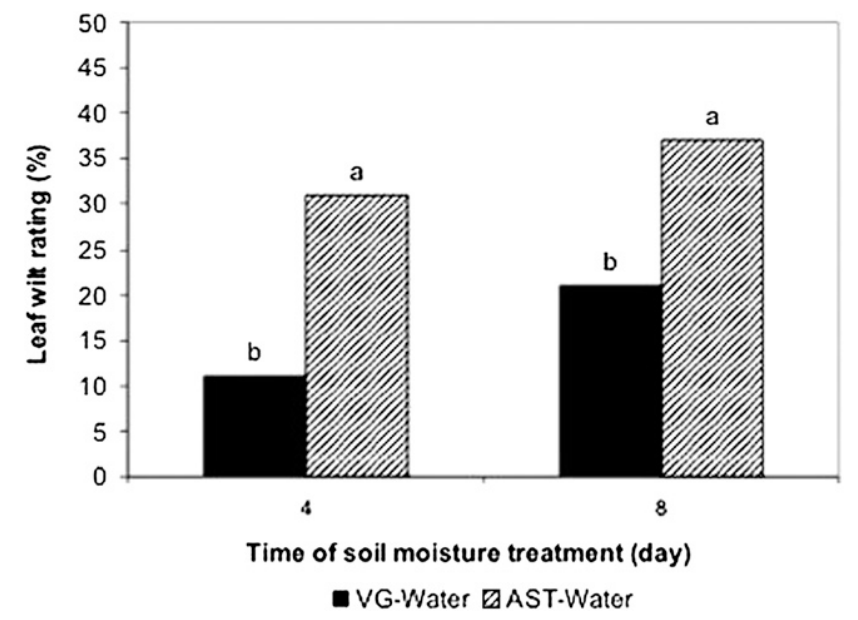

Fig. 3. Leaf wilt rating (\%) in two tall fescue cultivars under drought stress conditions (the soil moisture content reduced to $\approx 26 \%$ container capacity in 8 d). Bars marked with the same letter for each sampling date are not significantly different at $P \leq 0.05$. VG-water and AST-water indicate "Van Gogh' and 'AST7002' under drought stress conditions.

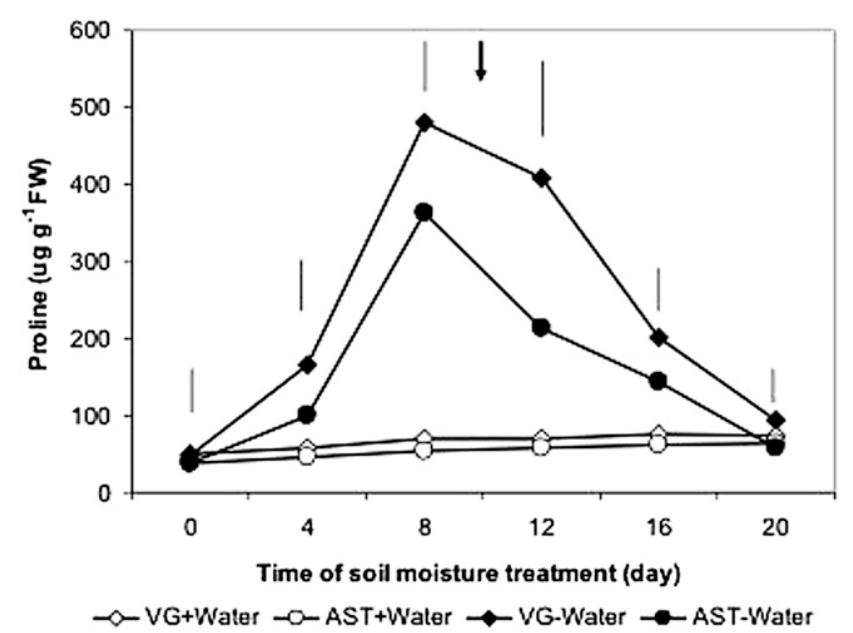

Fig. 4. Leaf proline content in two tall fescue cultivars under well-watered ( $90 \%$ container capacity) and drought stress conditions (the soil moisture reduced to $\approx 26 \%$ container capacity in $8 \mathrm{~d}$ and then rewatered at Day 10 and brought back to $90 \%$ container capacity for recovery). Vertical bars represent least significant difference $(0.05)$ for treatment comparison at each sampling date. VG+ water and AST+ water indicate 'Van Gogh' and 'AST7002' under well-watered conditions; VG-water and ASTwater indicate 'Van Gogh' and 'AST7002' under drought stress conditions. The arrow indicates the time of re-watering. 
content in 'Van Gogh' was $50 \%$ greater than that in 'AST7002'. No difference in ABA content was found between cultivars under well-watered conditions.

The leaf IAA content decreased during drought stress and recovery periods (Fig. 6). No difference in IAA content was found between cultivars under drought stress and well-watered conditions.

The leaf ZR declined during drought stress in both cultivars and recovered after watering in 'Van Gogh' but not in 'AST7002' (Fig. 7). The leaf ZR content in 'Van Gogh' was $43 \%$ (at Day 8 ) and $49 \%$ (at Day 16) higher, respectively, when compared with that in 'AST7002'. No difference in ABA content was observed between cultivars under well-watered conditions.

\section{Discussion}

The results of this study indicate that drought stress reduced turfgrass quality, reduced LWC, and increased leaf proline content. Drought-tolerant 'Van Gogh' had greater visual quality rating, LWC, and proline content than drought-sensitive 'AST7002' under drought stress conditions. This is in agreement with previous studies in tall fescue (Zhang et al., 2009) and tobacco (Dobra et al., 2010). Drought tolerance is defined as the ability of plants to continue to be functional

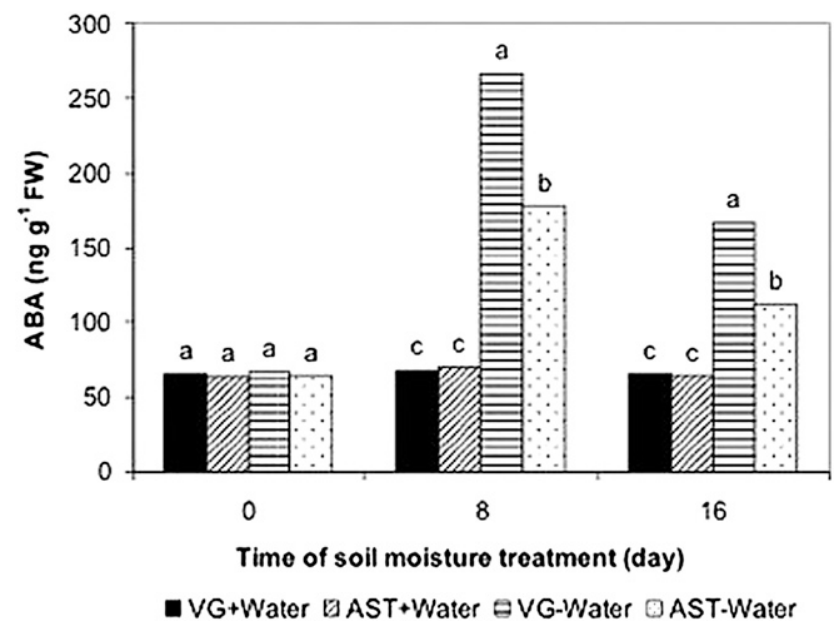

Fig. 5. Leaf abscisic acid (ABA) content in two tall fescue cultivars under well-watered $(90 \%$ container capacity) and drought stress conditions (the soil moisture reduced to $\approx 26 \%$ container capacity in $8 \mathrm{~d}$ and then re-watered at Day 10 and brought back to $90 \%$ container capacity for recovery). Bars marked with the same letter for each sampling date are not significantly different at $P \leq 0.05$. VG+ water and AST+ water indicate 'Van Gogh' and 'AST7002' under well-watered conditions; VG-water and ASTwater indicate 'Van Gogh' and 'AST7002' under drought stress conditions.

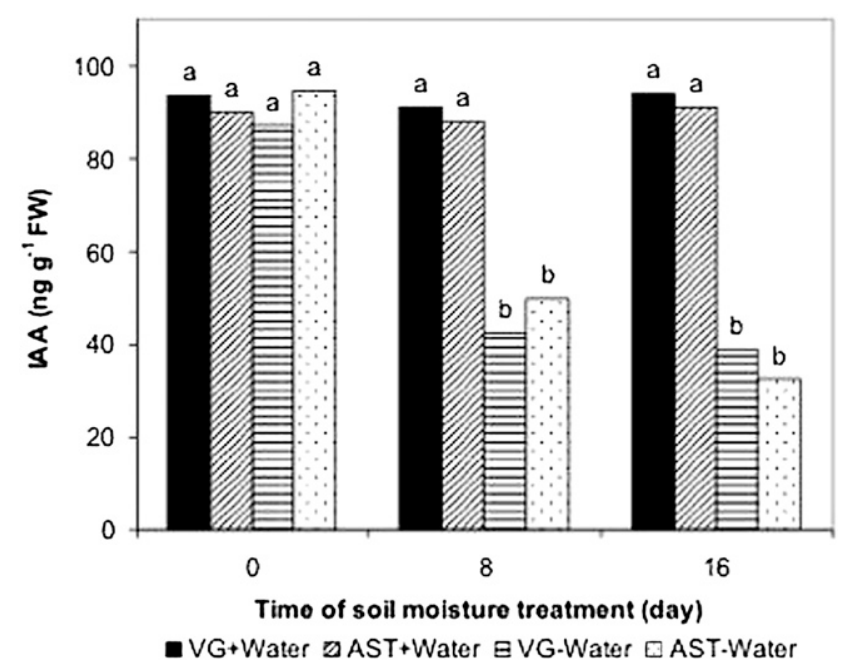

Fig. 6. Leaf indole-3-acetic acid (IAA) content in two tall fescue cultivars under well-watered $(90 \%$ container capacity) and drought stress conditions (the soil moisture reduced to $\approx 26 \%$ container capacity in $8 \mathrm{~d}$ and then re-watered at Day 10 and brought back to $90 \%$ container capacity for recovery). Bars marked with the same letter for each sampling date are not significantly different at $P \leq 0.05$. VG+ water and AST+ water indicate 'Van Gogh' and 'AST7002' under well-watered conditions; VG-water and AST-water indicate 'Van Gogh' and 'AST7002' under drought stress conditions. at reduced tissue water potentials. Droughttolerating mechanisms often involve the maintenance of turgor (by accumulation of solutes) and/or desiccation tolerance (by protoplasmic resistance; Jones et al., 1981). In response to drought stress, plants undergo $\mathrm{OA}$ in which proline plays an important role. Recent studies have shown that proline not only acts as an osmotic protectant, but also an antioxidant. Accumulated proline is thought to participate in stress-protective functions as antioxidants and stabilization of macromolecules during drought (Seki et al., 2007). Dobra et al. (2010) noted that proline overexpressing tobacco plants had lower osmotic potential and alleviated cytokinin decline during drought stress relative to wild-type plants.

The results of this study also indicate that ABA increased, whereas IAA and ZR declined in response to drought stress. 'Van Gogh' had higher ABA and ZR than 'AST7002' as measured at the end of drought stress (Day 8). This is consistent with previous studies (Bano et al., 1993; Roberts and Dumbroff, 1986; Zhang et al., 2009; Zhang and Ervin, 2004). Rapid production of ABA is a common response to moisture stress in higher plants. As soil dries, ABA synthesis in roots increases and it is transported into leaves and induces stomatal closure. Endogenous levels of ABA often increase five- to 10 -fold when transpiration exceeds water uptake (Beardsell and Cohen, 1975). Under drought stress conditions, ABA concentrations in leaves can increase up to 50 times (Taiz and Zeiger, 2010). Exogenous application of ABA to fully hydrated leaves has been shown to induce stomatal closure (Kriedmann et al., 1972). Hu et al. (2010) reported that ABA may induce antioxidant defense systems and suppress toxicity of reactive oxygen species (ROS) under drought stress. Waterland et al. (2010) found that ABA application delayed leaf wilting and extended shelf life in bedding plants. This suggests that ABA may be associated with drought tolerance because of its functions as a signal molecule for regulating stomatal closure and antioxidant defense. The higher LWC and less leaf wilting in 'Van Gogh' may be associated with its higher ABA content under drought stress.

Cytokinins have antisenescence and antioxidant functions. Cytokinin metabolism is a dynamic balance between biosynthesis, formation of cytokinin conjugates that may retain some degree of cytokinin activity, and the catabiotic reactions resulting in loss of biological activity (Hare et al., 1997). Closure of stomata, as a result of water deficit, and consequent interruption of $\mathrm{CO}_{2}$ and $\mathrm{O}_{2}$ exchange may result in excess accumulation of ROS such as superoxide radical $\left(\mathrm{O}_{2}^{-}\right.$; Sairam et al., 1998). Reactive oxygen species may damage membrane lipids, protein, DNA, and other cell components. Cytokinin can scavenge ROS and protect cell functions. Zhang and Ervin (2004) reported that exogenous application of ZR can increase endogenous $\mathrm{ZR}$ content and improve drought 


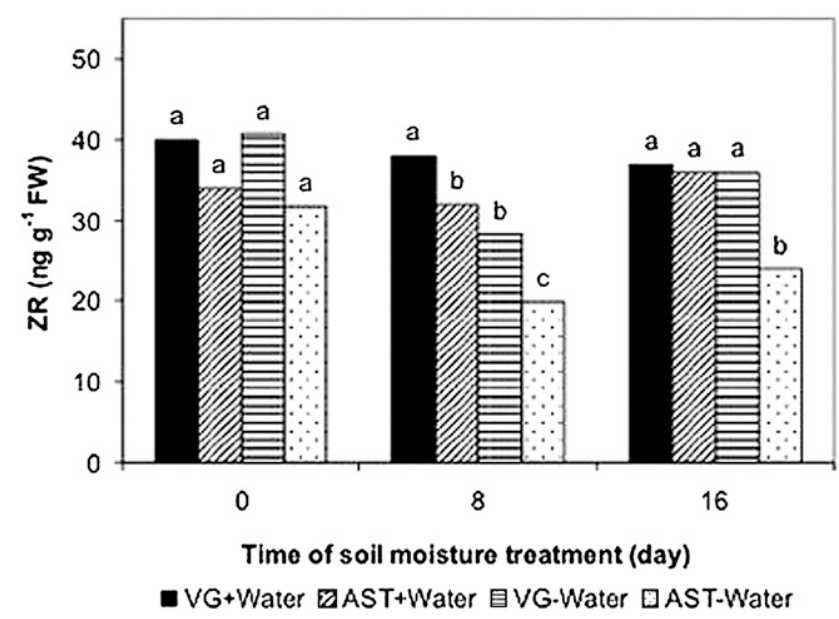

Fig. 7. Leaf zeatin riboside (ZR) content in two tall fescue cultivars under well-watered $(90 \%$ container capacity) and drought stress conditions (the soil moisture reduced to $\approx 26 \%$ container capacity in $8 \mathrm{~d}$ and then re-watered and brought back to $90 \%$ container capacity for recovery). Bars marked with the same letter for each sampling date are not significantly different at $P \leq 0.05$. VG+ water and AST + water indicate 'Van Gogh' and 'AST7002' under well-watered conditions; VG-water and AST-water indicate 'Van Gogh' and 'AST7002' under drought stress conditions.

tolerance in creeping bentgrass. The results of our study suggest that the cultivar with relatively higher cytokinin content may have greater drought tolerance than the one with less cytokinin content under drought stress.

The results of our study showed that the relatively drought-tolerant cultivar (Van Gogh) had lower IAA content under drought and higher IAA content after re-watering when compared with the relatively drought-sensitive cultivar (AST7002). This is consistent with the previous study by Xie et al. (2003) who found that drought stress resulted in a decrease in IAA content in wheat (Triticum spp.) leaves. However, Zhang et al. (2009) reported that the tall fescue with higher IAA and ZR content had greater drought tolerance, and exogenous IBA and IAA-containing organic amendments increased root biomass, leaf IAA content, and drought tolerance in tall fescue. Taiz and Zeiger (2010) noted that low concentrations $\left(10^{-10}\right.$ to $\left.10^{-9} \mathrm{M}\right)$ of exogenous auxin promote root growth, whereas higher concentrations $\left(10^{-6} \mathrm{M}\right)$ inhibit root growth because auxin induces the production of ethylene, which inhibits root growth. The results of our study suggest that IAA may not be consistently related to root biomass and drought tolerance.

In summary, the results of this study indicate that drought stress caused decline in turfgrass quality and LWC. Leaf proline and ABA increased, whereas IAA and ZR content decreased in response to drought stress. After re-watering, turfgrass quality and LWC increased and leaf proline and ABA content decreased. Zeatin riboside content increased in 'Van Gogh', but not in 'AST7002' as the grass was re-watered. 'Van Gogh' had greater levels of proline, ABA, and cytokinin content relative to 'AST7002' under drought stress. The results suggest that selection and use of the cultivars with higher proline, ABA, and ZR content may improve tall fescue growth and quality under drought stress conditions.

\section{Literature Cited}

Alves, A.A.G. and T.L. Setter. 2004. Abscisic acid accumulation and osmotic adjustment in cassava under water deficit. Environ. Exp. Bot. $51: 259-279$

Bano, A., K. Dorffling, D. Bettin, and H. Hahn. 1993. Bascisic acid and cytokinins as possible root-to-shoot signals in xylem sap of rice plants grown in drying soil. Aust. J. Plant Physiol. 20: 109-115.

Bates, L.S. 1973. Rapid determination of free proline for water-stress studies. Plant Soil 39: 205-207.

Beardsell, M.F. and D. Cohen. 1975. Relationship between leaf water status, abscisic acid levels and stomatal resistance in maize and sorghum. Plant Physiol. 56:207-212.

Carrow, R.N. and R.R. Duncan. 2003. Improving drought resistance and persistence in turf-type tall fescue. Crop Sci. 43:978-984.

Desikan, R., M. Cheung, J. Bright, D. Henson, J.T. Hancock, and S.J. Neill. 2004. ABA, hydrogen peroxide and nitric oxide signaling in stomatal quard cells. J. Expt. Bot. 55:205-212.

Dobra, J., V. Motyka, P. Dobrev, J. Malbeck, I.T. Prasil, D. Haisel, A. Gaudinova, M. Havlova, J. Gubis, and R. Vankova. 2010. Comparison of hormonal responses to heat, drought and combined stress in tobacco plants with elevated proline content. J. Plant Physiol. 167:13601370.

Domash, V.I., R.F. Protsko, V.A. Vasyuk, S.V. Shumikhin, L.V. Ermolitskaya, and T.P. Sharpio. 2006. The content of abscisic acid and the activities of proteinases and trypsin inhibitory proteins, in the germinating seed of common beans under water stress conditions. Appl. Biochem. Microbiol. 42:97-100.

Edlund, A., S. Eklof, B. Sundberg, T. Moritz, and G. Sandberg. 1995. A microscale technique for gas chromatography-mass spectrometry measurements of picogram amounts of indole-3acetic acid in plant tissues. Plant Physiol. 108: 1043-1047.

Gonzalez, L. and M. Gonzalez-Vilar. 2001. Determination of relative water content, p. 207212. In: Reigosa Roger, M.L. (ed.). Handbook of plant ecophysiology techniques. Kluwer Academic Publishers, Dordrecht, The Netherlands.
Hare, P.D., W.A. Cress, and J. van Staden. 1997. The involvement of cytokinins in plant responses to environmental stress. Plant Growth Regulat. 23:79-103.

Hu, X.L., R.X. Liu, Y.H. Li, W. Wang, F.J. Tai, R.L. Xue, and C.H. Li. 2010. Heat shock protein 70 regulates the abscisic acid-induced antioxidant response of maize to combined drought and heat stress. Plant Growth Regulat. 60:225-235.

Itai, C. 1999. Role of phytohormones in plant responses to stresses, p. 287-301. In: Lerner, H.R. (ed.). Plant response to environmental stresses: From phytohormones to genome reorganization. Marcel Dekker, New York, NY.

Jones, M.M., N.C. Turner, and C.B. Osmond. 1981 Mechanisms of drought resistance, p. 15-35. In: Paleg, L.G. and D. Aspinal (eds.). The physiology and biochemistry of drought resistance in plants. Academic Press, Sydney, NY.

Kriedmann, P.E., B.R. Loveys, G.L. Fuller, and A.C. Leopold. 1972. Abscisic acid and stomatal regulation. Plant Physiol. 49:842-847.

Lopez-Garbonell, M., L. Allegre, and H. van Onckelen. 1994. Changes in cell ultrastructure and endogenous abscisic acid and indole-3acetic acid concentration in Fatsia japonica leaves under polyethylene glycol induced water stress. Plant Growth Regulat. 15:165-174.

Musgrave, M.E. 1994. Cytokinins and oxidative processes, p. 167-178. In: Mok, D.W.S. and M.C. Mok (eds.). Cytokinins: Chemistry, activity, and function. CRC Press, Inc., Boca Raton, FL.

National Turfgrass Evaluation Program. 2008. May 2010. <http://www.ntep.org/data/tf06/ tf06_09-9/tf0609t25.txt>.

Nordstrom, A., F.A. Jacobs, and L. Eliasson. 1991. Effect of exogenous indole-3-acetic acid and indole-3-butyric acid on internal levels of the respective auxins and their conjugation with aspartic acid during adventitious root formation in pea cuttings. Plant Physiol. 96:856-861.

O'Donnell, R.W. 1973. The auxin-like effects of humic preparations from leonardite. Soil Sci. 116:106-112.

Pustovoitova, T.Z., N.E. Zhdanova, and V.N. Zholkevich. 2004. Changes in the levels of IAA and ABA in cucumber leaves under progressive soil drought. J. Plant Physiol. Russian 51:513-517.

Roberts, D.R. and E.B. Dumbroff. 1986. Relationships among drought resistance, transpiration rates, and abscisic acid levels in three northern conifers. Tree Physiol. 1:161-167.

Sairam, R.K., P.S. Deshmukh, and D.C. Saxena. 1998. Role of antioxidant systems in wheat genotypes tolerance to water stress. Biol. Plant. 41:387-394.

Sakurai, N., M. Akiyama, and S. Kuraishi. 1985. Role of abscisic acid and indole acetic acid in the stunted growth of water-stressed, etiolated squash hypocotyls. Plant Cell Physiol. 26:15-24.

SAS Institute Inc. 2004. SAS 9.1.3. SAS Institute Inc., Cary, NC.

Seki, M., T. Umezawa, K. Urano, and K. Shinozaki. 2007. Regulatory metabolic networks in drought stress responses. Curr. Opin. Plant Biol. 10:296-302.

Strivastava, L.M. 2002. Plant growth and development: Hormones and environment. Academic Press, San Diego, CA.

Taiz, L. and E. Zeiger. 2010. Plant physiology. 5th Ed. Sinauer Associates, Inc., Sunderland, MA.

Thimann, K.V. 1987. Plant senescence: A proposed integration of the constituent processes, p. 1-19. In: Thomson, W.W. and E.A. Nothnagel (eds.). Plant senescence: Its biochemistry 
and physiology. Amer. Soc, Plant Physiol. Rockville, MD

Waddington, D.V., R.N. Carrow, and R.C. Shearman. 1992. Turfgrass. Agron. Monogr. 32. ASA, CSSA, and SSSA, Madison, WI.

Wang, C., A. Yang, H. Yin, and J. Zhang. 2008. Influence of water stress on endogenous hormone contents and cell damage of maize seedlings. J. Integr. Plant Biol. 50:427-434.

Waterland, N.L., C.A. Cambell, J.J. Finer, and M.L. Jones. 2010. Abscisic acid application enhances drought stress tolerance in bedding plants. HortScience 45:409-413.

Xiao, L.T., C.J. Lovatt, I. Bertling, and Z.K. Liao. 2001. Differences in endogenous hormones between normal and dwarfing trifoliate orange. HortScience 36:567-614.

Xie, Z.J., D. Jiang, W.X. Cao, T.B. Dai, and Q. Jing. 2003. Relationships of endogenous plant hormones to accumulation of grain protein and starch in winter wheat under different postanthesis soil water statuses. Plant Growth Regulat. 41:117-127.

Xiong, L., K.S. Schumarker, and J.K. Zhu. 2002. Cell signaling during cold, drought, and salt stress. Plant Cell 14(suppl):165-183.

Yang, J.C., J.H. Zhang, Z.Q. Wang, Q.S. Zhu, and W. Wang. 2001. Hormonal changes in the grains of rice subjected to water stress during grain filling. Plant Physiol. 127:315-323.

Yang, T.X., A.Z. Wei, Y. Zheng, H. Yang, X.N. Yang, and R. Zhang. 2007. Simultaneous determination of 8 endogenous hormones in apricot floral bud by high performance liquid chromatography. Chinese Journal of Analytical Chemistry 35:1359-1361.

Zhang, X. and E.H. Ervin. 2004. Cytokinin-containing seaweed and humic acid extracts associated with creeping bentgrass leaf cytokinins and drought resistance. Crop Sci. 44:1737-1745.
Zhang, X., E.H. Ervin, G.K. Evanylo, and K.C. Haering. 2009. Impact of biosolids on hormone metabolism in drought-stressed tall fescue. Crop Sci. 49:1893-1901.

Zhang, X., E.H. Ervin, G. Evanylo, C. Sherony, and C. Peot. 2005. Biosolids impact on tall fescue drought resistance. J. Residuals Science \& Technology 2:173-180.

Zhang, X. and R.E. Schmidt. 1999. Antioxidant responses to hormone-containing product in kentucky bluegrass subjected to drought. Crop Sci. 39:545-551.

Zhang, X. and R.E. Schmidt. 2000. Hormonecontaining products' impact on antioxidant status of tall fescue and creeping bentgrass subjected to drought. Crop Sci. 40:13441349.

Zhu, J.K. 2002. Salt and drought stress signal transduction in plants. Annu. Rev. Plant Biol. $53: 247-273$. 